\title{
CHARACTERISTICS OF HELIUM ION BEAMS FROM MULTICUSP SOURCE AND STUDY OF BEAM TRANSPORT
}

\author{
M. Sasao\#, M. Nishiura, NIFS-509-5292, Japan \\ S. K. Guharay, U. of Maryland, MD20742 \\ T. Kuroda, M. Hamabe, Chubu U. 480, Japan \\ H. J. Ramos U. of the Philippines-1101, M. Wada, Doshisha U., 610-0321, Japan,.
}

\begin{abstract}
A test stand with a multicusp type $\mathrm{He}^{+}$ion source and an electrostatic transport system was built for the study of beam characteristics at relatively low energy, $\mathrm{E}<10 \mathrm{keV}$, and beam transport in a space-charge dominated region with $\beta(=v / c)<0.0025$. The measured normalized beam emittance $(90 \%)$ of the $\mathrm{He}^{+}$beam extracted from a compact multicusp source is about $0.08 \pi \mathrm{mm}$-mrad for the emission current density of about $5-15 \mathrm{~mA} / \mathrm{cm}^{2}$ at 6 $9 \mathrm{kV}$. An electrostatic quadrupole transport system (ESQ) is designed for this beam. Preliminary experimental results show that the ESQ has a potential to transport a beam without any significant emittance growth over a length of about $50 \mathrm{~cm}$.
\end{abstract}

\section{INTRODUCTION}

With the goal to generate a high energy $(1.7 \mathrm{MeV}) \mathrm{He}^{0}$ beam probe for a burning plasma experiment[1], we have been developing an intense $\mathrm{He}^{-}$ion beam [2]. $\mathrm{A} \mathrm{He}^{-}$ beam can only be produced effectively from $\mathrm{He}^{+}$via a two step elecetron capture process in an alkali metal gas cell, such as $\mathrm{Li}, \mathrm{Na}, \mathrm{Mg}, \mathrm{K}, \mathrm{Rb}$, or Cs. Because the optimum energy for these processes was reported to be around $6 \mathrm{keV}$ [3], the essential point of the development is extraction of an intense $\mathrm{He}^{+}$beam at relatively low energy.

Another key issue is the transport of a high perveance beam, with a good focusing property onto an aperture of the charge exchange cell. The aperture should be small enough to minimize the alkali vapor leakage. In

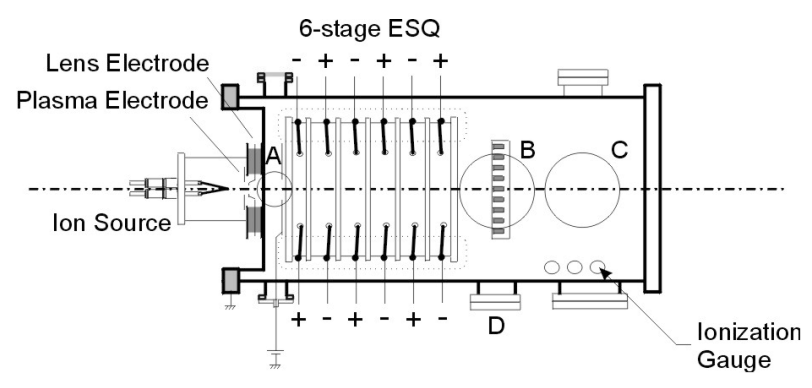

transporting a high perveance beam, the charge neutralization due to background

gas pressure usually prevents the beam expansion. We cannot use this method in our experiment. The ionization cross section of $\mathrm{He}^{+}$is very low in this region $\left(2 \times 10^{-18}\right.$ $\mathrm{cm}^{2}$ ). At higher gas pressure, the collisional charge exchange process of $\mathrm{He}^{+}$with the residual helium gas results into a ground state $\mathrm{He}^{0}$. This cross section is $5 \times 10^{-}$ $16 \mathrm{~cm}^{2}$. A long-life, $10-300 \mu \mathrm{s}, \mathrm{He}^{-}\left({ }^{4} \mathrm{Pj}\right)$ is produced only through its metastable state. Therefore, in order to avoid any beam loss and produce $\mathrm{He}^{-}$effectively, a low gas pressure, $<<10^{-2}$ Torr, should be maintained.

One of the solutions of this problem is to employ an efficient transport system using eletrostatic lenses[4-7]. In the present paper, an experimental study of a low energy $\mathrm{He}^{+}$beam characteristics, the design of the transport system for it, and its initial results are described.

\section{EXPERIMENTAL ARRANGEMENT}

A schematic diagram of the test stand with a $\mathrm{He}^{+}$ion source and an electrostatic transport is shown in Fig. 1. A helium plasma is generated by two hair-pin type of tungsten filaments $(0.4 \mathrm{~mm}$-diameter $)$ in an $8.5 \mathrm{~cm}$ diameter and $10 \mathrm{~cm}$-long compact multicusp ion source, which can be operated either in a pulsed mode or in a DC mode with discharge current up to $15 \mathrm{~A}$. An $\mathrm{He}^{+}$beam is extracted from a set of three electrodes of $6 \mathrm{~mm}$-diameter. The ion source itself is biased at acceleration voltage, $\mathrm{V}_{\mathrm{acc}}$, and the second electrode is negatively biased $\left(-\mathrm{V}_{\mathrm{dec}}\right)$, and the beam is accelerated to $\mathrm{V}_{\text {acc }}+\mathrm{V}_{\text {dec }}$ in the first extraction gap. The third electrode is grounded, and the beam is decelerated by $\mathrm{V}_{\mathrm{dec}}$ so that the final beam energy is $\mathrm{eV}_{\mathrm{acc}}$.

\footnotetext{
"Work supported in part by Japanese Society of Promotion of Science, grant \# 10480110

One of the authors (S. K. Guharay) thankfully acknowledges Prof. M. Reiser for introducing the idea of ESQ transport and for many valuable discussions. Dr. C.K. Allen's work for developing the K-V code is also acknowledged.

\#Email: sasao@nifs.ac.jp
}

Figure 1: Schematic View of Experimental Arrangement 


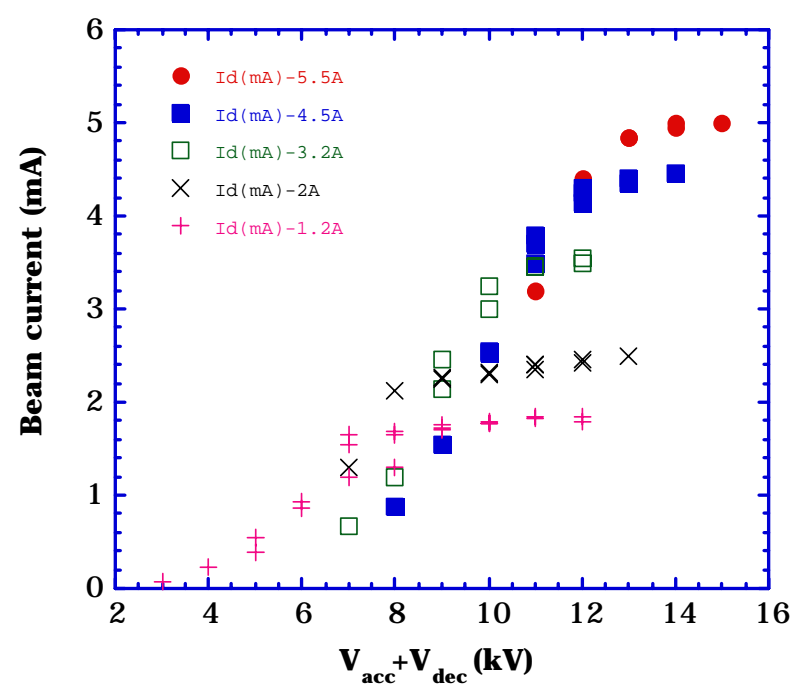

Figure 2 The extraction voltage $\left(\mathrm{V}_{\text {acc }}+\mathrm{V}_{\text {dec }}\right)$ dependence of the $\mathrm{He}^{+}$beam current measured by the large faraday cup ( with a $36 \mathrm{~mm}$-diam.) at $15 \mathrm{~cm}$ down stream.

The electrostatic transport system, developed at Maryland, is composed of six ESQ lenses. The geometrical parameters are given in Table 2 of the previous work[7]

There are several diagnostic ports, and the diagnostic tools developed are: a large Faraday cup for total beam current measurement, a Faraday cup array for beam profile measurements, and three types of emittance gauge. The large Faraday cup was specially designed to measure full beam currents, avoiding spurious contributions due to co-moving electrons and any secondary electrons. It has an entrance aperture diameter of $36 \mathrm{~mm}$, a pair of magnets, and a caterpillar shaped electron collector.

Two emitance gauges are slit-and-multi-electrode type; one of which has insulators between electrodes, and the other has a structure so that no dead layer exists between them. The third one is a pepper-pot type gauge[8]. Detail description of them and comparison will be reported elsewhere.

\section{BEAM EXTRACTION CHARACTERISTICS}

The $\mathrm{He}^{+}$beam characterization was performed without the transport system. Fig. 2 shows the extraction voltage $\left(\mathrm{V}_{\mathrm{acc}}+\mathrm{V}_{\text {dec }}\right)$ dependence of the $\mathrm{He}^{+}$beam current measured by the large Faraday cup at $15 \mathrm{~cm}$ down stream from the exit of the source. Here the discharge current was varied so that the

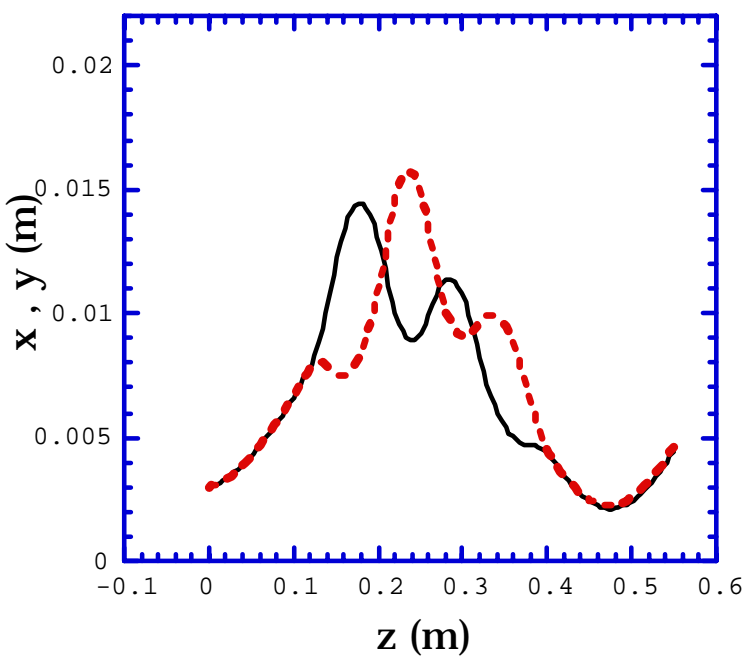

Figure 3 The beam envelope in $\mathrm{x}$ and $\mathrm{y}$ direction in the $\mathrm{ESQ}$, where $\mathrm{z}$ is the direction of the propagation, for a case of $1 \mathrm{~mA}, 8 \mathrm{kV}$ beam with $\mathrm{r}=3 \mathrm{~mm}, \mathrm{r}^{\prime}=10 \mathrm{mrad}$. The lower graph shows the voltage applied on the lenses.

space charge limited region and that limited by the source emission can be clarified. Extensive studies of the source property in higher power region will be reported elsewhere. The beam profiles measured at various $\mathrm{z}$ locations show that the beam is strongly diverging.

The normalized beam emittance $(90 \%)$ of the $\mathrm{He}^{+}$beam extracted from the source is measured by the slit-andmulti-electrode emittance gauge, and it is about $0.08 \pi$ $\mathrm{mm}$-mrad at the current density of about $5-15 \mathrm{~mA} / \mathrm{cm}^{2}$ at $6-9 \mathrm{kV}$. The pepper pot measurement gives the value of about $0.075 \pi \mathrm{mm}$-mrad.

\section{BEAM TRANSPORT STUDIES}

\subsection{ESQ design}

In order to transport such a diverging high-perveance beam, and to focus it onto the entrance of the charge exchange cell, an efficient low-energy beam transport system [7] has been considered. The original design was made for the transport of $30 \mathrm{~mA}, 35 \mathrm{kV} \mathrm{H}^{-}$beam for the SSC injector. The present beam, 1-5 mA, 6-10 $\mathrm{kV} \mathrm{He}^{+}$, however, has higher perveance $\mathrm{K} \simeq 0.004-0.02$. A set of lens parameters, which can transport over about $50 \mathrm{~cm}$, has been found after a wide range of parameter survey using a simulation code solving the $\mathrm{K}-\mathrm{V}$ envelope equations [6]. Fig. 3 shows the beam envelope in $\mathrm{x}$ and $\mathrm{y}$ directions in the ESQ, for a case of $1 \mathrm{~mA}, 8 \mathrm{kV}$ beam with the initial beam radius, $r$, of $3 \mathrm{~mm}$, and the initial beam divergence, r', of $10 \mathrm{mrad}$. 


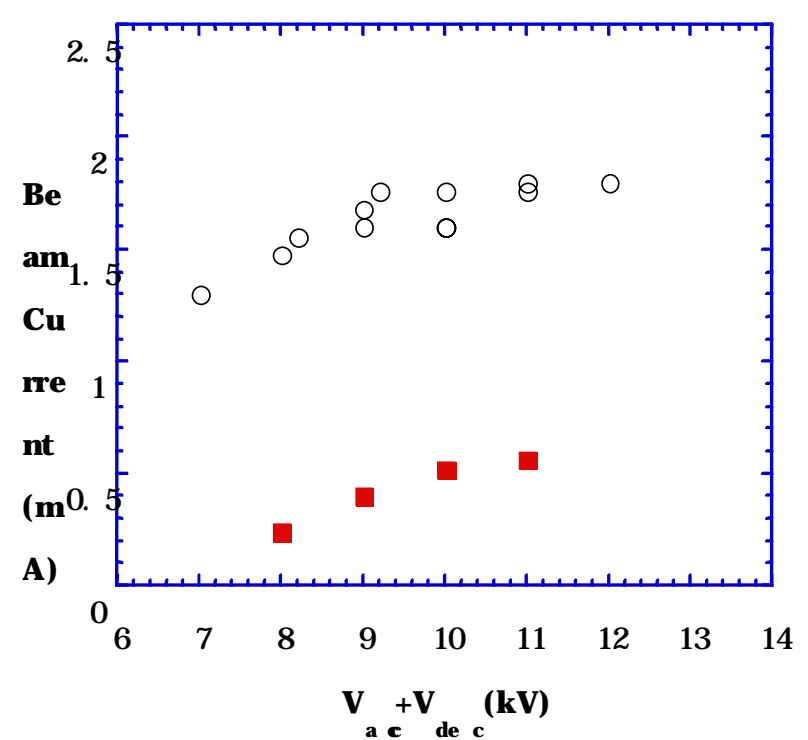

Figure 4 The $\mathrm{He}^{+}$beam current measured at about $10 \mathrm{~cm}$ down stream from the exit of the ESQ. The circles are with ESQ excitation, and squares are without ESQ. The beam energy is $8 \mathrm{keV}$.

\subsection{Experimental results with ESQ}

Preliminary experiment has been carried out to examine the ESQ performance and to characterize the beam after the transportation. The twenty four electrodes are biased by using twelve independent power supplies. The voltages are set at the optimum values determined by the simulation calculation. In the Fig. 4 are shown the total beam current measured by the large Faraday cup at about10 $\mathrm{cm}$ down stream from the exit of the ESQ: with ESQ excitation (circles), and without excitation (squares). The $70 \%$ of the whole beam from the source are detected at the $60 \mathrm{~cm}$ downstream. Considering the beam loss between the source and the entrance of the ESQ, the results in Fig. 4 show that the most of the beam is successfully transported by ESQ.

The focusing property was examined by the Faraday cup array. Figure 5 shows one example of the $8 \mathrm{kV}, 2 \mathrm{~mA}$ beam profile measured at about $60 \mathrm{~cm}$ down stream, for the case ESQ excited (solid line) and that without ESQ excitation (dashed line). Although this position does not correspond to the beam waist as shown in Fig. 3, we can expect that the charge exchange cell can be set well apart from the ESQ, with $100 \%$ beam throughput.

The emittance was also measured at $10 \mathrm{~cm}$ down stream from the exit of ESQ, for a $2 \mathrm{~mA}, 8 \mathrm{keV}$ beam. The one dimensional normalized emittance was about $0.11 \pi \mathrm{mm}-$ mrad. Considering the $\pm 15 \%$ ambiguity of the emittance evaluation, the emittance growth in the ESQ transport system seems to be low.

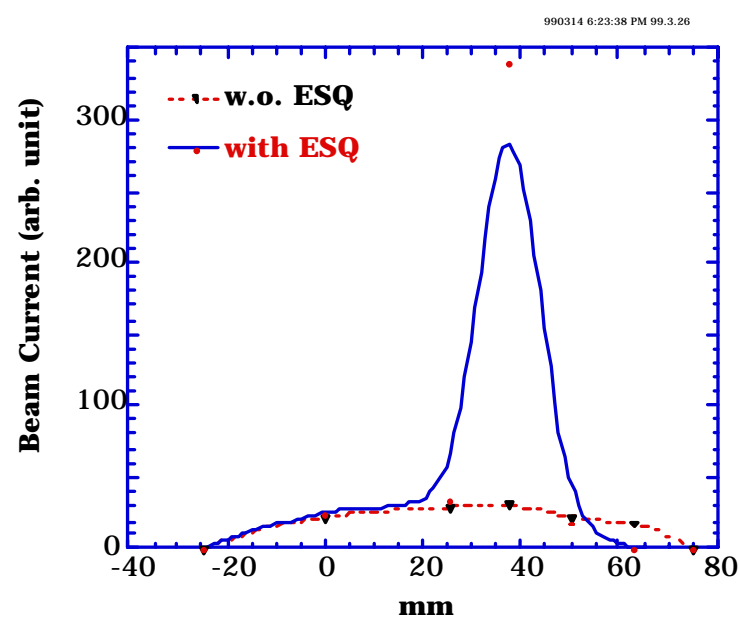

Figure 5 The beam profile measured at about $60 \mathrm{~cm}$ down stream, for the case ESQ excited (solid line) and that without excitation(dashed line). The beam energy is 8 $\mathrm{keV}$, and the initial beam current $2 \mathrm{~mA}$.

In conclusion, the present experimental results indicate that the ESQ has a potential to transport a $\mathrm{He}^{+}$beam without any beam loss, and without any significant emittance growth over a length of about $50-\mathrm{cm}$, and to focus it on to a charge exchange cell well apart from the source.

\section{REFERENCES}

[1] D.E.Post et al., Fusion Technology 1 (1978), 355 M.Sasao et al.,Fusion Technology 10 (1986), 236

[2] M.Sasao et at, Rev. Sci. Instrum. 69-2 (1998) 974

[3] R.J. Girnius et at, Nucl. Instrum. Methods, 137 (1976) 373.

[4] Theory and Design of Charged Particle Beams, M. Reiser (Wiley, N.Y.) 1994.

[5] S. K. Guharay, C. K. Allen, and M. Resier, in "High-brightness beams for Advanced Accelerator Applications" edited by W.W. Destler and S. K. Guharay, AIP Conf. Proc. No 253, 1992, pp 67-76.

[6] C.K. Allen, S.K. Guharay, and M. Reiser, Proc. 1995 Particle Accelerator Conference, Dallas, Texas (IEEE, New York, 1996), p. 2324.

[7] S.K.Guharay et al., Nucl. Instrum. Methods A339 (1994) 429.

[8] S.K.Guharay et al., Rev. Sci. Instrum. 67 (1996) 2534 . 